\title{
Boedo e Florida
}

Adolfo Prieto

Tradução de Renata Mourão e Luiz Carlos Jackson

Poucos temas na literatura argentina contemporânea suscitaram tanto interesse, tamanha hipérbole nos juízos, tal profusão de testemunhos, como o trabalho dos grupos que irromperam nos anos imediatos à Primeira Guerra Mundial. $\mathrm{Na}$ verdade, a curiosidade atual justifica-se pelo prestígio que alguns integrantes daquela geração alcançaram com suas obras de maturidade, e basta pensar que nomes como os de Borges, Bernárdez, González Lanuza, Marechal, Girondo, Castelnuovo ou Mariani constituem alguns dos capítulos mais substanciosos de nossa literatura, para compreender esse tipo de interesse reflexivo, similar ao que desperta a infância dos próceres ou a origem das comunidades ilustres.

Não é esse tipo de interesse, contudo, que orientará estas considerações. A geração literária surgida no primeiro pós-guerra, ainda desprovida de suas obras de maturidade, sem a perspectiva posterior do êxito e da estima da crítica, oferece matéria para uma análise válida desde que consiga evitar a tentação da crítica miúda e a reiteração de esquemas já por demais conhecidos.

Comecemos por apontar as circunstâncias histórico-sociais que permitiram o desenvolvimento das atividades literárias em um marco auspicioso e excepcional. A Primeira Grande Guerra e a eclosão da Revolução Russa foram, cada um com suas dimensões específicas, acontecimentos que modificaram os níveis do horizonte histórico. O século XIX conclui-se realmente com esses fatos e uma nova era se abre ou parece se abrir com novos 
meios de realização, forte otimismo e boa dose de fé no futuro. A Argentina, confinada pela geografia e pela história nos extramuros do mundo, acusa o impacto dos fatos e busca conectar-se à torrente circulatória das novas ideias e de suas fórmulas expressivas. Antes de terminar o conflito bélico, em 1916, a figura de Yrigoyen cristalizava o desejo pelo sufrágio livre. O caudilho, com teimosia e atitude esotérica, facilitou o acesso ao poder de setores amplos da classe média. Em 1918, a Reforma Universitária - correlata do triunfo radical no meio acadêmico - agita as mentes juvenis e confirma a presunção, amplamente sustentada em outros lugares e por outros motivos, de que a juventude liquidará o mundo dos velhos. Na Europa verifica-se certa petulância, certo vitalismo explosivo, um menosprezo acentuado pelo passado e uma absoluta irresponsabilidade pelo futuro. Ortega diria que se inaugura o sentido festivo da vida depois de um século especialmente acumulativo e laborioso, e serão naturalmente os jovens os protagonistas do alegre consumo. A presidência de Alvear, 1922-1928, demarca essa variante argentina de uma tendência quase universal. Aqui coincide a repercussão de um período insólito de bonança mundial com o decidido florescimento da prosperidade interior; uma política social relativamente benigna com o desfrute de uma liberdade de expressão facilitada. Valorizem-se de qualquer modo cada um desses elementos: em conjunto, favoreceram a eclosão de um clima especialmente propício, sem antes nem depois na história cultural do país.

Impressionam o número e a variedade das revistas literárias - Proa, Inicial, Valoraciones, Los Pensadores, Martín Fierro, Claridad, La Revista de América, Campana de Palo -, a incrível tiragem de algumas dessas publicações 10 mil exemplares mensais de Claridad; 20 mil, um número afortunado, de Martín Fierro -, a ressonância dos concursos literários, o eco de alguns episódios protagonizados por escritores ou a propósito de escritores - desde a notável simulação de César Tiempo sob o pseudônimo de Clara Beter até o afastamento de Leumann do jornal La Nación; desde os ruidosos banquetes para visitantes famosos à paródia grosseira que o escritor Francisco Soto y Calvo realizou sobre a Exposição da atual poesia argentina, antologia utilíssima preparada por Pedro Juan Vignale e César Tiempo. A literatura difunde-se, é levada em conta como nunca; os escritores jovens, usufrutuários diretos da conjuntura favorável, ocupam-se de si mesmos e de suas obras com uma desenvoltura sem precedentes. Manifestos, programas, revistas orais, exposiçōes radiofônicas, reportagens jornalísticas. Dia após dia a nova literatura define-se ante o público, atribui a si mesma rótulos mais ou menos 
chamativos, envolve-se em rivalidades de escolas, distende-se em cálidos elogios de camaradagem.

Com as exceções naturais, a meia centena de jovens que começa a escrever nesses anos (cômputo de nomes que persistem) parece sentir uma consciência unitária de grupo, uma necessidade de reconhecer-se no conjunto, que dilui as diferenças estéticas ou ideológicas e converte a luta de facçôes em rixas mais ou menos domésticas, de conciliação adequada ao empenho verbal comprometido.

Fortes pela transferência a uma unidade superior, por serem jovens em um mundo em que a maturidade sofria o estigma do fracasso; a revelação da própria pujança, do próprio valor constitui-se como um dos aspectos característicos daquela geração. No primeiro número de Proa (segunda época, ano 1924) lê-se esta declaração redonda:

Logo veio o florescimento dos jovens que fatigavam a imaginação em buscas venturosas. E vieram à luz cenáculos e revistas cuja força pletórica irrompeu na impaciência, com incompreensões e ódios. Pretendeu-se malograr o movimento com um silêncio excessivamente glacial para ser sincero, mas pouco a pouco as classes cultas compreenderam a magnitude do fenômeno e, depois de observar-nos de longe com curiosidade mesclada com dúvida, deram-nos sua sanção mais ampla com a esplêndida convivência que acaba de se iniciar entre elas e os artistas, sem distinção de bandeiras ${ }^{1}$.

Já assinaladas, sumariamente, as circunstâncias favoráveis em que essa geração irrompe na literatura, e antecipados os vínculos que notoriamente definem um matiz familiar ao conjunto, será oportuno deter-se nas duas tendências mais conhecidas, supostamente antitéticas, e que tanto nas polêmicas como nos livros pretenderam outorgar um sentido diverso à literatura.

Florida e Boedo, designaçōes topográficas precisamente transferidas ao campo em que o meramente estético se separa dos conteúdos ideológicos ou, melhor dito, da propaganda ideológica, representam em nossa literatura o velho dilema que a fórmula horaciana, dulce et utile, pretendeu resolver no mais difícil dos equilíbrios imagináveis. Florida, rua do ócio distraído, era um bom nome para alcunhar a variante local do conceito de gratuidade na arte; Boedo, rua de trânsito fabril em um bairro fabril, uma excelente bandeira para agitar as consciências com adequadas formas de subversão. Florida mirava a Europa e as novidades estéticas do pós-guerra; Boedo mira-
1. Há mais otimismo que veracidade nessa declaração: os jovens sofreram resistência sem trégua por muitos dos intelectuais mais notáveis da geração vigente. $\mathrm{O}$ primeiro deles, Lugones. "Leopoldo Lugones foi, ele sozinho, a geração anterior à nossa, e nos odiou com rancor leonino porque adivinhava em nós o inimigo que contava com a cumplicidade do tempo", diria González Lanuza em 1942, recordando as tensóes do conflito geracional. Giusti, já prestigiado por seu trabalho à frente da revista Nosotros, daria esta cáustica opinião sobre a nova literatura, em uma reportagem solicitada por $E l$ Día, de Montevidéu, em janeiro de 1926. O jornalista adiantara o tema da reportagem - a nova sensibilidade: "Giusti: Com franqueza, não acredito que exista. Uma nova retórica, sim, é possível. Todo poeta é uma nova e fresca sensibilidade. Por isso é poeta. Mas esses poetas não se encontram em todas as esquinas. $\mathrm{O}$ mais frequente é aquele que se acomoda com o novo palavreado (que deixa de ser novo apenas nascido). Os poetas assim, palavrosos, são legião. Em menos de um ano os tenho visto passar à 'nova sensibilidade' e inventar metáforas de novo cunho, ainda que de gosto e felicidade discutíveis, e versos tipográficos, entre garotos que ontem ainda victorhugueavam em insossos alexandrinos. "Jornalista: Mas o fazem por necessidade espiritual ou por pose? "Giusti: Até onde isso seja necessidade espiritual, não sei. Mas penso que é coisa exterior, superficial, pegadiça, imitada, passageira. O artifício, entretanto, é manifesto. O que significa afixar 'revistas murais' como al- 
guns jovens de Montevidéu disseram que iriam fazer, imitação do que fizeram alguns de Buenos Aires, suponho que imitação de alguns de Paris? Pretendem fazer arte para o povo? Eles são os primeiros que devem rejeitar minha absurda hipótese; porque, caso contrário, eu a rejeito. Não sendo assim, a quem se dirige esse cartaz? Para que editar um envelope com versos impressosem tinta violeta, como acaba de fazer um uruguaio amigo meu, muito querido e talentoso? Eoqueo senhor me diz do banquete ambulante acredito que em ônibus - que estão preparando para esse néscio Gómez de la Serna? "Piadas? Brincadeiras de 'patotas' alegres? Nesse caso, que contem comigo, pois não sou de pedra. Mas isso éliteratura? Em nome disso se pode negar todo o passado, a todos os que amaram e sentiram pelo menos como eles, e expressaram com maior emoção? Não. Fomos todos iconoclastas aos vinte anos, mas esses jovens da nova sensibilidade exageram. Que pedantes!" (reproduzido em Nosotros, n. 200-201, fev. 1926).

2. Eduardo González Lanuza, Aquelarre, Buenos Aires, 1927.

3. Na Argentina, o termo "modernismo" refere-se ao movimento literário iniciado no final do século XIX - centralizado nas figuras do nicaraguense Rubén Darío e do argentino Leopoldo Lugones-, contra o qual as vanguardas da década de 1920 se insurgem (N. T.). va a Rússia e se inflamava com o sonho da revolução universal. As origens de ambas as designações são difíceis de serem verificadas e foram aventados vários nomes e intenções para explicá-las ${ }^{2}$. De qualquer modo, deve-se notar o modo eficaz com que tais nomes destacam a polarização desse processo literário.

Como todo estado de pureza, a literatura pura apenas deu fruto visível no grupo Florida e foram antes aproximações e esforços voluntários do que resultados concretos. Como caso extremo, pode-se destacar o exemplo de Eduardo González Lanuza, autor de Prismas, quintessência do ultraísmo, e de Aquelarre, "livro de imaginação no mais vasto sentido da palavra”, em cujo prólogo pode-se ler o seguinte:

Quero deixar claro aqui que de jeito nenhum pretendi sustentar em meus contos nenhuma ideia filosófica, ética, nem de qualquer classe de inquietudes alheias à literatura. São contos literários. Nada mais e nada menos... Não interpretem, tampouco, minha atitude como um repúdio à literatura psicológica. Explico-me: acredito que tanto o conto como o romance psicológico, que pessoalmente me entusiasmam quando o autor é um Jack London ou um Goncharov, enquadram-se melhor na monografia científica, no documento antropológico, do que no campo puramente literário.

Os escritores de Florida, em seu conjunto, estavam preocupados, principalmente, em aclimatar ao nosso solo o ultraísmo espanhol, introduzido por Borges em 1921. O ultraísmo, como se sabe, enfatizou o uso da metáfora, matou ou pôs em perigo de morte a seiva tropical do modernismo ${ }^{3}$, estimulou o rigor mental e a cautela. $\mathrm{O}$ próprio Borges historiou a introdução e a influência do ultraísmo em um texto pouco frequentado hoje:

Neste passado morno de apenas três anos que não fizeram de mim um forasteiro, começava o ultraísmo em terras americanas, com sua vontade de renovação, já travessa e brincalhona em Sevilha, mas que ressoou aqui de modo perseverante e apaixonado. Refiro-me à época de Prisma, jornalzinho mural que infundiu nas paredes cegas e nos nichos ermos uma antecipação transitória e cuja claridade sobre as causas era uma janela aberta diante de céus distintos; e de Proa, cujas três páginas eram soltas como esse espelho tríplice que torna movediça e variada a graça silente da mulher que se expressa. Para nossa sensibilidade, os versos contemporâneos eram inúteis, encantamentos desgastados, e por isso nos parecia urgente a ambição de fazer uma lírica nova. Estávamos fartos da insolência das palavras e da 
indecisão musical tão apreciada pelos poetas do século XIX; queríamos uma arte singular e eficaz na qual a formosura fosse tão inegável como o entusiasmo que o mês de outubro desperta na carne juvenil e na terra. Exercitamos a imagem, a sentença, o epíteto, de modo conciso ${ }^{4}$.

Essa depuração da linguagem poética apoiava-se, além disso, de acordo com a melhor tradição da vanguarda europeia (tradição que Borges respeitou em seu manifesto ultraísta de 1921), na exclusão de todo arrasto emocional e do intento de incorporar circunstâncias ao poema. Quase todos os poetas iniciados no ultraísmo - e Borges o primeiro - se apartaram, contudo, desse princípio e aplicaram a nova linguagem poética a temas propícios ao memorialismo e à contextualização miúda. Buenos Aires, ou melhor, seus arrabaldes, converteram-se logo em matéria poética por excelência, até o ponto de gerar uma retórica nova, já clássica pelo prestígio e pela circulação de numerosos achados. Armazéns rosados, casebres azuis, ruas enternecidas de árvores...

A busca da cor local, dos tipos característicos, o criollismo ou, para empregar uma expressão generalizada, a poesia folclórica, segundo definição de Cansinos Assens aplicada ao primeiro livro de Ricardo Molinari ${ }^{5}$, foi uma variante curiosa da vanguarda literária de Florida. É fácil perseguir nos livros mais representativos desse grupo provas abundantes dessa inclinação um tanto paradoxal e, frequentemente, snob, mas esses livros refletem apenas uma parte da obsessão criollista: a outra se dispersou e se esgotou em excursões coletivas aos subúrbios portenhos, em discussões de café, em uma ou outra divagação sociológica, na contemplação admirada de entardeceres, no registro erudito dos mais velhos tangos e milongas suburbanos. Para El hombre que está solo y espera, síntese dessa atitude deambulatória, mais descomprometida que reflexiva, o autor desse ensaio, Raúl Scalabrini Ortiz, escreveu sugestivamente:

O autor [...] realizou, ademais, uma forte campanha pelo reconhecimento das qualidades portenhas, como redator de La Nación, El Mundo, El Hogar e Noticias Gráficas. Mas sua melhor obra, a mais indiscutivelmente portenha, está em suas incursões, em suas vagâncias pelas ruas, em suas despreocupações, em seu amor à cidade jamais desmentido...

Estas palavras, escritas em 1931, sob o rescaldo de experiências vividas recentemente, encontrariam sua contrarréplica em outras que Borges escre-
4. Prólogo ao livro de Nora Lange, La calle de la tarde, Buenos Aires, 1925. Este trecho foi traduzido por Sergio Miceli.

5. Em Verde y dorado en las letras americanas, Madri, 1947. 
6. "El escritor argentino y la tradición”, conferência pronunciada em 1951, reproduzida em Otras inquisiciones, Buenos Aires, 1953.

7. Esta é a lista de colaboradores de Martín Fierro, com exclusão dos artistas plásticos e críticos musicais: Girondo, Rojas Paz, Palacio, Nalé Roxlo, Franco, Córdoba Iturburu, Rega Molina, Olivari, Raúl González Tuñón, Ganduglia, Piñero, Ledesma, Borges, Cané, Caraffa, Nora Lange, Vignale, Bernárdez, Amorín, López Merino, González Lanuza, Marechal, Pedroni, Pondal Ríos, Cancela, Julio Irazusta, Scalabrini Ortiz, Salas Subirat, Mastronardi, Fijman, Molinari, Petit de Murat. veria vinte anos mais tarde para denunciar a ilusão dos caçadores da cor lo$\mathrm{cal}^{6}$, e sua versão irônica nas excelentes páginas em que Leopoldo Marechal transmutou em matéria romanesca para o seu Adán Buenosayres (1948) as inquietudes extravagantes daqueles jovens escritores da vanguarda literária.

Para se apreender outra característica do grupo Florida não é necessária a consulta de seus livros representativos. $\mathrm{O}$ bom humor, o desrespeito por alguns dos valores estabelecidos, a alegria zombadora, a atitude lúdica e certa petulância inocente encontraram melhor acolhida nas revistas do que nos livros, principalmente em Martín Fierro (1924-1927), publicação ágil, amena e aberta a todas as tendências de vanguarda.

A história de Martín Fierro, entusiasticamente traçada por Oliverio Girondo ${ }^{7}$, um de seus fundadores, e a do grupo Florida são quase sobrepostas. Nessa revista colaboram não apenas os poetas inscritos nas fórmulas mais destacadas de vanguarda: também se avizinham alguns de tendência conservadora ou próximos ao conservadorismo artístico, mas a quem seduz a possibilidade da encenação, do jogo de palavras, da sátira, ou o simples contato da camaradagem profissional. Com o pseudônimo de Héctor Castillo, Ernesto Palacio escreve a Epistola a Nalé Roxlo:

A punto estuve de escribirte una tirada

En verso blanco a la manera de Max Rhode,

Pero como eso es cosa que ya está muy gastada,

Te escribo en prosa bien rimada

Para que Lugones no se incomode.

Nalé Roxlo, feliz de ti

Que harto de la ciudad, te fuiste un día

A intervenir la provincia de Jujuy

Que tenía subvertida su poesía,

Llevando en tus flacas maletas

(Prestadas)

Un haz de flechas envenenadas,

Entre las medias y las camisetas.

Feliz de ti, pues conseguiste

Desvincularte con un esfuerzo superior,

Como si se tratara de un tenaz acreedor,

De este Buenos Aires imbécil y triste

Que no merece ni el honor de un chiste, 
Aunque Méndez Calzada sea el feliz autor.

De esta ciudad que es un destierro

Para quien no consigue medrar en la política

$O$, lo que es casi igual, robar en los recodos...

(Hay el oasis de Martín Fierro,

Pero tiene una sombra raquítica

Que no da sombra para todos.)

Yo quisiera también marcharme al Norte.

A Buenos Aires no hay quien lo soporte.

$Y$ como eres hombre influyente,

Te pido

Que en un descuido

Del interventor o el intendente,

Robes un nombramiento y me lo mandes inmediatamente.

Necesito un empleo

De unos trescientos pesos en que no se trabaje.

Envía un nombramiento por correo

Junto con el pasaje

$y$ al día siguiente me pondré en viaje.

E em todos os números é possível certificar-se, sob formas que vão desde a ditirâmbica gazetilha crítica até a piada mais ou menos afiada e urticante, a preocupação por destacar ao interesse do público os nomes e as obras dos jovens iniciados. Assim, em Parnaso satírico e nos Epitafios, as duas seções mais celebradas de Martín Fierro, é frequente encontrar, lado a lado com as figuras consagradas de Lugones, Gálvez ou Capdevila, os nomes de Girondo, González Lanuza, Rega Molina, Nora Lange e quase todos os integrantes dessa geração.

Aqui reposa González

Lanuza, el vate cuadrado;

El pobre murió atacado

De "Prismas" intestinales.

A. B. $C$

Silencioso, solo, en pace,

En este oscuro rincón 
8. Os desconcertados colaboradores de Claridadinterpretaram assim aquele fervor eleitoral: "Desfacedor de viejos y caducos regimenes:/ cuando al cabo traspongas los anhelados limites/ del gran salón presidencial:/ Escucha nuestros ruegos, comprende nuestros gestos/ y dadnos consulados, cátedras y otros puestos, $/ ;$ Hombre genial y sin igual!. Jorge Luis Borges, Leopoldo Marechal, Nicolás Olivari, Raúl y Enrique González Tuñón, Pablo Rojas Paz, Francisco Luis Bernárdez, Francisco López Merino y otras necesidades. Presidente honorario: Victrola Oyhanarte" (A "El hombre", 28 de abril de 1928).
Córdova Iturburu yace...

Se amaba hasta el paroxismo

$Y$ murió de admiración

que se produjo a sí mismo.

El hijo de H. D.

Su vida inquieta reposa

Aqui, Oliverio Girondo:

Gesto fiero, mirar hondo

$Y$ extraño poeta en prosa.

Persiguiendo nuevos temas

Iba, y lo mató un tranvía

Mientras el guardia leía

Su libro "Veinte poemas".

$$
\text { E. } M \text {. }
$$

Martín Fierro deixou de ser publicada por causa de um desacordo entre o diretor Evar Méndez e um grupo de colaboradores que postulavam a candidatura de Yrigoyen para a presidência da República. É muito curioso que um grupo de escritores que defendia a separação entre a literatura e a possibilidade de influir no mundo em que se vive encampasse esse patrocínio eleitoral ${ }^{8}$. Mas eles o fizeram e, qualquer que fosse a consciência e os objetivos de cada um dos envolvidos, o certo é que com esse ato marcaram o fim de uma revista que representava uma época. Yrigoyen assumiu o poder pela segunda vez, porém dois anos depois um golpe militar impediu a continuidade constitucional e se converteu no marco de uma mudança profunda tanto do contexto internacional como da ordem interna. Martín Fierro desaparece em 1927; o golpe militar de Uriburu ocorre em 1930. Devem ser situadas nesse ínterim as últimas manifestações do grupo Florida propriamente dito. Desaparecem as revistas inquietas e desrespeitosas; perde-se o gosto pela discussão e pelo escândalo literário. Os banquetes rituais e as conversas nos cafés perdem a força de outrora. A literatura, como estado público, silencia-se. $\mathrm{O}$ mundo e o país haviam se transformado, e os jovens que cinco anos antes faziam tanto ruído entraram na etapa da maturidade, quando a obra, para fazer-se pessoal, prefere com frequência o isolamento. As datas de 1922 e 1928 constituem-se, assim, como os marcos cronológicos do grupo Florida, ainda que para cada um dos casos individuais a cronologia deva se flexibilizar. Para Girondo, por exemplo, come- 
ça antes de 1922 e se conclui apenas em 1932, com a publicação de Espantapájaros. Para Borges, apesar do que declarou prematuramente ${ }^{9}$, terminou em 1930, com Evaristo Carriego, seu deleite reflexivo de Palermo e seu interesse pelo compadre ${ }^{10}$ : "cultor da coragem".

A cronologia de Boedo, diferentemente, é menos precisa no que se refere à realização de um tipo de literatura praticada e à sobrevivência de certa atitude ante a literatura social em nosso país. $\mathrm{O}$ grupo esclareceu ou tentou esclarecer os princípios teóricos; ocupou-se de difundir os clássicos da literatura revolucionária; propôs-se a não utilizar a literatura senão como instrumento para revolver as consciências e promover a imagem de um mundo melhor. É óbvio que, com esse ponto de partida e com tais objetivos, estivesse menos condicionado às mudanças na ordem política ou econômica, às modas artísticas, ao desejo de perfeição formal e à singularidade da obra literária. Livre dessas contingências, Boedo foi, provavelmente, mais do que uma geração demarcada por limites cronológicos estreitos, podendo ser entendido como uma escola ou um capítulo extenso de nossa literatura contemporânea. Nesse sentido, tem razão Alvaro Yunque quando inclui, na sua antologia Poetas sociales de la Argentina, no capítulo "Poetas de Boedo", trabalhos escritos muito depois de 1930, atendendo mais à definição de certa literatura que aos alcances do termo designativo. $\mathrm{O}$ verdadeiro limite para a literatura propugnada pelo grupo Boedo corresponderia, então, ao ciclo vital de seus integrantes e de alguns discípulos consequentes. Nesse ciclo, interfere a aparição da doutrina que o Primeiro Congresso de Escritores Soviéticos (1934) definira com o nome de realismo socialista. A nova doutrina afetou apenas os hábitos e os propósitos dos boedistas e, às vezes, como ocorreu com Elias Castelnuevo, foi ostensivamente negada, mas ela marca uma solução de continuidade entre a literatura de Boedo e permite falar, desde esse momento, de uma nova concepção da literatura de esquerda.

A história de Boedo também foi registrada por alguns de seus integrantes e não a repetirei em detalhes. O grupo constituiu-se ao redor da revista Los Pensadores, que começou a ser publicada em 1922, mudando seu nome para Claridad em $1926^{11}$. Já foi dito que o estouro da revolução russa cristalizou em uma literatura coerente os ecos dispersos e isolados que a injustiça social vinha despertando há algum tempo. Alvaro Yunque, ao prefaciar uma edição de Obras selectas de González Prada (1923), resume muito bem o seu sentido:

Seu tom brioso deve ecoar na juventude americana se esta quer pensar, se já se encontra farta dessa turba de frangos que se fazem de literatos, de donos da verdade
9. "Conversou-se excessivamente sobre Boedo e Flori$\mathrm{da}$, escolas inexistentes. Acredito, entretanto, na correlação da paróquia, da seção eleitoral, do bairro, com a literatura." "Página sobre la lírica hoy”, em Nosotros, ago./ set. 1927 .

10. O termo designa uma espécie de "malandro" portenho (N.T.).

11. No primeiro número se anuncia: "Claridad aspira a ser uma revista em cujas páginas se reflitam as inquietudes do pensamento esquerdista em todas as suas manifestações. Desejamos estar mais próximos das lutas sociais do que das manifestações puramente literárias". Um ano depois (fevereiro de 1927), um editorial esclarece: "Esta publicação não é uma publicação socialista, nem comunista, nem anarquista. $\mathrm{O}$ fato de que alguns dos colaboradores pertençam ao partido socialista ou comunista, ou sejam georgistas ou anarquistas, não significa que todos nós pensemos do mesmo modo". "Não somos sectários. Nossa amplitude de horizontes nos permite abrigar todos os escritores livres que queiram expor livremente suas ideias. Nós não nos ajustamos a nenhuma bíblia, seja a bíblia vermelha ou negra. Somos livres de nascimento... Somos inimigos de toda política. Mais do que um programa teórico, nos ajustamos a um programa de ação... Somos partidários da ação em qualquer terreno. Não somos partidários da doutrina estrita. Não estamos sacramentados nem temos nada de catecúmenos ou doutrinários. Não vivemos para acender velas a Lênin ou a Bakunin, senão para revolucionar as 
consciências... É necessário avançar sempre. Somos homens de vanguarda. Queremos caminhar à frente de todo movimento artístico ou ideológico. Qualquer iniciativa nova encontra entre nós um apoio franco. Lutamos sozinhos contra todos. Sustentamos que o homem se dignifica por seus atos e não por suas ideias. Estamos fartos de discursos bonitos e ações canalhas. Agora, quem tiver ouvido para ouvir, que ouça." que se fazem de filósofos como poderiam se fazer de palhaços. A hora é essa! A tragédia está nos queimando o rosto, iluminemos as chamas do incêndio onde ardeu uma civilização decrépita; ressoemos ainda nos ouvidos, mais que o troar da metralha assassina, o do derrubamento social. A hora é esplendorosamente homérica. Não era mais possível que, em jardins bonitos, à luz de lustres à veneziana, seguíssemos cantando madrigais à lua, galanteios às colombinas ou dançando ao som do sistro mitológico como cacatuas ou pulcinelas.

Essa sensibilidade para captar um dos grandes acontecimentos da história contemporânea e o ânimo de favorecer entre nós as circunstâncias adequadas para um clima revolucionário foram os meios pelos quais a literatura de Boedo tentou se estabelecer. A empresa exigia, sem dúvida alguma, maior esforço que o necessário para assimilar a última moda artística da França, uma renúncia mais firme às recompensas tradicionais da literatura e uma decidida clarificação e retificação dos métodos conhecidos. Florida aproximou-se da literatura pura, sem cumprir com suas exigências ascéticas; Boedo aproximou-se da literatura revolucionária, mas carregava muitos lastros para satisfazer seus próprios ideais. Fizeram uso, ainda, do velho realismo crítico para denunciar os aspectos sombrios do mundo e de um lirismo tolstoiano para exaltar a virtude dos humildes e dos submersos. Deformavam com gosto a realidade para forjar de contragolpe a imagem de uma vida e de um mundo melhor, mas a denúncia poucas vezes constituiu-se como uma análise profunda das causas que tornavam o mundo intolerável, e o lirismo não superou os limites de uma piedade decididamente mitigadora.

As características de Boedo parecem muito nítidas quando as deduzimos de seus autores mais representativos: Castelnuovo, Barletta, Yunque, Mariani, mas se diluem bastante, como ocorre com o grupo Florida, quando se observam as figuras secundárias, ou quando se aplica uma lente de aumento ao movimento das revistas, ao anedotário mais ou menos verossímil, aos empréstimos e traslados mais ou menos ruidosos, às numerosas atitudes compartilhadas. Claridad, por exemplo, autodefinida como "tribuna do pensamento esquerdista", cuidadosamente atenta aos grandes problemas internos e externos, fiscal rigorosa dos abusos, defensora valente dos direitos humanos, onde quer que ocorressem, ocupava-se demoradamente da vida literária portenha e concedia uma especial atenção às obras e aos projetos dos autores do grupo Florida. Participava, também, do espírito lúdico com que aqueles costumavam julgar os fatos literários e as pessoas vincula- 
das à literatura. Assim, neste avulso de Claridad (n. 6, dez. 1926), sob o título de "El infantilismo de vanguardia":

Os que fazem as estúpidas piadas do periódico Martín Fierro, e que de vez em quando esperneiam, publicam esta vez um desenho em cores de Norah Borjes, que é uma calamidade.

Ela não seria admitida nem no concurso para crianças de Caras y Caretas. O que não é um obstáculo para que um asno erudito escreva um artigo, ou o que quer que seja, elogioso, no qual diz entre outras coisas muito divertidas que "a linha obedece neles (nos desenhos) a um impulso interior, a uma urgência poética”.

Se os desenhos de Borjes têm alguma relação com a poesia, será seguramente com a poesia de Jorge Luis Borges, o de "El general Quiroga va al muere en coche" e outras bobagens do bairro de Palermo.

A Borjes, já demonstrou em sua exposição, está na infância do desenho, como Pedro Figari está na senilidade. Por isso tanta afinidade de espírito os aproxima. Mas se a jovenzinha Borjes e o velhinho Figari são pintores, Leopoldo Marechal é o primeiro poeta da América... atacado de infantilismo de vanguarda, que é uma doença da moda.

Ou nestas décimas atribuídas a Fernández Moreno (n. 161, 23 jun. 1928):

\section{I}

Metido en mi sobretodo

es decir, metido dentro

me paseo por el centro,

todo encharcado de lodo,

componiendo de este modo

con mis líricas recetas

$y$ mis rimas $y$ mis tretas,

poemas conmovedores

a todos los aviadores,

para "Caras y Caretas".

II

Debajo de mi paraguas,

pues esta noche gotea,

mi vista se regodea

contemplando las enaguas 
12. Roberto Mariani, que desatou a polêmica, formulou também a melhor síntese do antagonismo Florida/Boedo, com clara contraposição de termos: vanguardalesquerda; ultraísmo/realismo; Martín Fierro e ProalLos Pensadores e Claridad; a "gregueria"/o conto e o romance; a metáforalo assunto e a composição; Ramón Gómez de la SernalFiodor Dostoievski. Na mesma nota, Mariani interpreta o conceito de realismo: "Aceitemos o termo 'realismo' por falta de outro mais exato e preciso, e vejamos se nos entendemos. Somente com má-fé se explicam de una niña que a las aguas

desafia, brava y fiera;

mas, lo quiera o no lo quiera,

debo atender los pedidos

de "La Prensa": unos sentidos

versos para verdulera.

Ou neste jogo de palavras da mais pura extração martinfierrista:

Dice un humorista sin ortografia: "Este señor Oria ya no tiene remedio, a menos que Dios mismo le diga un día: Sana Oria”.

Essas transgressões à severa linha social da revista mostram, com evidências de sobra, que muitos dos escritores jovens de Boedo se aferravam ainda ao conceito segundo o qual ser escritor implica uma condição substantiva, que admite diversas contingências, mas que suporta a todas elas na unidade e na dignidade superior do ofício. Admitem-se certas missões, cumprem-se determinados objetivos. Pode-se aceitar ou rechaçar tal concepção de mundo, mas no fundo, ou acima de tudo, se é escritor, ou seja, um amante da beleza e da habilidade de expressá-la verbalmente. Esteja claro, outra vez, que essas considerações não se referem aos integrantes mais importantes do grupo, mas afetam outros nada desdenháveis e, em conjunto, assinalam um curioso fenômeno sociológico-literário. A ambiguidade nas tomadas de posição, os conflitos entre atitudes políticas e escolha dos meios expressivos explicam assim a desconcertante dupla colaboração de vários escritores em Martín Fierro e em Claridad, mencionando apenas as revistas representativas, e as contraditórias preocupações de outros, como o mesmíssimo Roberto Mariani, excelente descritor da asfixiante vida do "proletariado de pescoço duro" e empenhado difusor da obra de Proust.

Nicolás Olivari, ao responder a "Encuesta sobre la nueva generación literaria” (Nosotros, ano XVII, 1923), toca no ponto central. À pergunta: "Existe entre o senhor e os escritores de sua idade uma orientação estética comum? Qual é ela?”, responde Olivari:

Acredito que sim. Tenho vários amigos que compartem comigo a admiração e o amor apaixonado pela literatura russa. Isso pode ser uma orientação em certo sentido, sobretudo em um conceito realista da literatura como expressão social. Contudo, esta pergunta é muito complexa. Além da preferência pelo realismo há uma 
orientação puramente estética, um culto formal, um carinho um pouco desmedido pela suntuosa beleza estilística. Nosso rico e harmonioso castelhano tem a culpa.

Esse canto de sereia perturbou muitos ouvidos até o momento em que não foram suficientes os traslados esporádicos à redação de uma ou outra revista, segundo os rumores do dia, mas foi necessária a criação de um novo órgão, capaz de conciliar as duras exigências da literatura social com os afagos da forma, a seriedade da missão assumida com o aditamento da alegria e do riso. A revista se chamou La campana de palo e em seu primeiro número (junho de 1925) o editor anônimo qualificava os colaboradores como netos, bisnetos e tataranetos de Tolstoi, Romain Rolland e Ghandi; e reclamava o dom da alegria e o direito de revestir de formas agradáveis e aprazíveis a humilde verdade que deviam dizer.

Em La campana de palo aparecem nomes como os de Gustavo Riccio, Alvaro Yunque, Raúl González Tuñón, Juan Guijarro e Luis Emilio Soto. Esses nomes dão muito peso a outro editorial anônimo da revista (no número 4), no qual se intervinha na polêmica desatada entre Martín Fierro e Los Pensadores a propósito dos alcances literários de Florida e Boedo. A polêmica, exagerada com o correr dos anos em sua virulência e em sua importância real, é interessante, contudo, como índice das formulações extremas da arte gratuita diante da arte comprometida ${ }^{12}$, e mais interessante ainda quando se comprova que entre ambos extremos flutuava uma terceira posição, uma terceira fórmula que reivindicou, sem sucesso, um lugar na polêmica e na história desse agitado debate. $\mathrm{O}$ articulista destacava o simplismo de Evar Méndez, diretor de Martín Fierro, ao pretender dividir a jovem intelectualidade argentina em dois blocos definidos: Florida e Boedo. Admite que haja "uma seção Florida, com uma inumerável corte de meninos que fabricam metáforas e se prostram diante do ídolo Ramón”, "com sua estética que responde ao conceito burguês da arte pela arte, com sua indiferença pelo aflitivo problema social, com seu desdém de aristocratas do pensamento (somente o são do dinheiro) a respeito da multidão que se apinha nos cortiços suburbanos". Mas Boedo, como grupo, não existe; aceita Castelnuevo com seu bem discutível realismo: um escritor não faz um grupo. Boedo, repete o articulista, não existe.

O que existe é uma literatura de arrabalde, feita por moços nascidos e criados nos arrabaldes [...]. Filhos do arrabalde, empregados, jornalistas quase todos eles, sofreram na própria carne a exploração capitalista e exteriorizaram seu descontenta- os nomes de Zola e Gálvez que nos impuseram como afronta. O realismo na literatura superou Zola e se desprendeu de incômodas companhias (principalmente da sociologia e das teses e objetivos moralizadores) ao mesmo tempo em que se desenvolvia vigorosamente com aportes novos ou rejuvenescidos, como o subconsciente. Em Exposición de la actual poesía argentina, pp. X-XI.

13. Os nomes de Castelnuevo, Barletta, Yunque, Riccio, Mariani e César Tiempo são, provavelmente, os que expressam com maior contundência as características com que se reconhece o grupo Boedo. Olivari e os irmãos González Tuñón representam, diferentemente, a zona de permeabilidade que existiu entre este grupo e o Florida. As dificuldades maiores de localização convergem no caso de Roberto Arlt. Arlt foi alternativamente reclamado por memorialistas de Florida e de Boedo, mas os argumentos aduzidos não são convincentes e referem-se somente a fatos externos. A amizade com Güiraldes, a publicação de dois contos de Arlt na revista Proa (1925), não provam absolutamente a adesão do romancista às fórmulas literárias de Florida nem ao tom vital de seus integrantes. Tampouco prova muito em favor de Boedo a origem social do escritor, suas leituras, a linguagem empregada em seus contos, a aparente preocupação social de seus romances. $\mathrm{O}$ individualismo anárquico de Arlt, seu ódio aos cenáculos e a característica de sua novelística (angústia, violência, irracionalismo) o afastam tão claramente de Florida como de 
Boedo, e ainda das coordenadas gerais que imprimem certa unidade à literatura desses anos. Não apenas o caso de Arlt suscita problemas de localização. Alberto Pinetta, em 1929, quer dizer, nos últimos momentos do enfrentamento Florida-Boedo, ensaiava esta distribuição, curiosa por mais de um motivo: "Ao grupo Florida pertencem Eduardo Mallea, 'estilista do tédio vertiginoso'; Raúl Scalabrini Ortiz, 'pescador da noite, escritor cidadão'; Francisco Luis Bernárdez, 'alucinado do tempo'; Leopoldo Marechal, 'explorador de horizontes onde dormem as palavras não ditas'; Roberto Arlt, 'vitalista, a quem Macedonio Fernández chama destruidor de estrelas'; Jorge Luis Borges, 'introdutor do ultraísmo'; Carlos Mastronardi, 'agricultor da manhã' e, ademais, Santiago Ganduglia, Nicolás Olivari, Lizardo Zía, Oliverio Girondo, Pedro Juan Vignale, Jacobo Fijman, Eduardo Keller Sarmiento, Evar Méndez. Entre os críticos e ensaístas, inclui os nomes de Ernesto Palacio, Carlos Alberto Erro, Alberto Prebich e Homero Guglielmini. Para Pinetta não pertenceram nem ao Boedo nem ao Florida: Roberto Mariani, Armando Cascella, Luis Emilio Soto, César Tiempo" ("La promesa de la nueva generación”, Síntesis, n. 29, 1929).

14. Juan Carlos Portantiero, Realismo y realidad en la narrativa argentina, Buenos Aires, 1961, p. 121, grifos de Adolfo Prieto.

15. Esse conflito ultrapassa, naturalmente, os problemas de técnica e conteúdos literários, e afeta as atitudes e a escolha de uma conduta deter- mento em uma literatura carregada de inquietudes, de ameaças e de ilusões. [...] Florida contra o Arrabalde. Assim é aceitável a assertiva. E a luta está disposta sem conciliações possíveis. Lá o Capital, aqui o Trabalho.

Termina a nota editorial com estas reflexões:

O que nos parece absurdo é que se queira enquadrar em Boedo, e com as características de uma literatura que vai do realismo patológico à truculência pornográfica, um grupo de escritores jovens que não participam dessa literatura e que formaram a sua cultura bem longe dela. Por que situar em Boedo, já que negam pertencer a tal grupo, tantos que não pertencem ao Florida?

A atitude separatista desse grupo foi mais um episódio isolado do processo literário desses anos, mas não há dúvida de que a mesma adquire características significativas quando se juntam todos aqueles dados vacilantes, contradições, idas e vindas, nos escritores que pela primeira vez entre nós postulavam uma literatura de esquerda coerente ${ }^{13}$. Que explicação aventar, fora do mero gosto literário, para dar sentido à atração que Martín Fierro exerceu em homens como Olivari, Raúl González Tuñón, César Tiempo, Aristóbulo Etchegaray, Roberto Mariani, ou ao martinfierrismo infiltrado com ares cúmplices nas austeras páginas de Claridad? Que sentido atribuir ao empenho com que os mesmos escritores que clamavam pelo incêndio da revolução universal discutiam os prêmios municipais de literatura e sua arbitrariedade distributiva?

Sem ânimo de ordená-las taxativamente, estas podem ser as razões que expliquem as mudanças de atitude e as frequentes contradições do grupo Boedo. A tradição literária de esquerda, débil, dispersa, marcada apenas pelo logro de tal ou qual resultado valioso, inabilitada para transmitir um conjunto útil de experiências ou de formulaçôes teóricas. A dificuldade de sustentar, até as últimas consequências, sem o apoio de uma força política, os supostos de uma literatura socialmente revolucionária. A dificuldade de escapar ao condicionamento de classe, com as pautas culturais e o horizonte de valores adquirido por educação ou por simples contágio do meio ambiente. Alguns escritores de Boedo provinham de lares proletários e realizavam trabalhos manuais para subsistir; outros provinham da pequena burguesia e se dedicavam ao jornalismo ou a trabalhos de escritório; ideologicamente constituíam um variado mosaico: anarquistas, socialistas, sindicalistas, georgistas, trotskistas, apristas e comunistas; esteticamente, era 
normal que oscilassem do naturalismo sensacionalista no qual incorre, às vezes, Elias Castelnuevo, ao carinho pela "suntuosa beleza estilística" de que fala Olivari. Refletindo sobre alguns desses argumentos, Juan Carlos Portantiero conclui que as diferenças essenciais entre Boedo e Florida não eram tão importantes. "Os dois grupos em que se subdividem a Geração de 22 se unem através de uma constante sociocultural: salvo exceções pessoais, a literatura de ambos os grupos era uma expressão do fracasso e da solidão espiritual das camadas médias urbanas" ${ }^{14}$.

É necessário retornar agora ao ponto de partida. Boedo e Florida não devem ser julgados pela projeção de algumas obras de maturidade ou pelo prestígio atual de alguns de seus membros. Ambas as tendências permitiram um processo singular em nossa história literária e, mais além dos resultados definitivos, acumularam suficiente experiência de acertos e erros, justificando, ainda hoje, um retorno às fontes. Florida tratou de atualizar o pulso literário; esteve alerta a todas as novidades postas em circulação pelas vanguardas europeias e, dos numerosos ismos exportáveis, apenas aclimatou um com sorte, o ultraísmo, com sua obsessão imaginativa e seu repúdio à retórica rubeniana. Logrou muitas metáforas felizes; mitificou com esforço estéril o arrabalde portenho; flexibilizou a língua; renovou a problemática da arte; desperdiçou talento e engenho com a imunidade que garante o exercício gratuito da literatura. Boedo teve quase que inventar sua própria tradição de literatura de esquerda; pagou copioso tributo à debilidade das formulações teóricas e à necessidade de se mover em um meio refratário, no qual os críticos não correspondiam exatamente aos leitores. Promoveu o interesse de multidões pela literatura social; mas se ateve excessivamente ao olhar entendido dos grupos minoritários e até se comprometeu, por contágio ou inércia, em devaneios e jogos verbais. Os escritores de Boedo sofreram, em sua maioria, o conflito dilacerador do intelectual burguês, a metade do caminho entre pautas culturais, das quais não consegue desprender-se, e objetivos históricos por cuja concreção joga seu destino individual ${ }^{15}$. Entenda-se que tiveram que sacrificar à eficácia o brilhantismo e que tiveram que assumir, com seus riscos, o incômodo papel de precursores ${ }^{16}$. minada. A maior parte dos escritores de Boedo aderiu à ação de partidos ou agrupamentos políticos, mas, não parecendo suficiente, alguns adotaram resoluções que pretendiam marcar a diferença entre o escritor social e o escritor que ia à literatura por simples razōes estéticas. É significativo esse gesto de Leónidas Barletta, segundo sugere o crítico Campos Carpio: "Leónidas Barletta, lutador incansável, cuja obstinação o levou até uma feira do bairro sul onde vendia batatas para demonstrar aos grã-finos de Florida que não tinha por que se ruborizar em realizar esse trabalho que outras pessoas menos cultas faziam...”.

16. Juan Carlos Portantiero pontua bem a importância histórico-cultural do grupo Boedo: "Boedo foi o primeiro impacto, em nossa narrativa, da revolução contemporânea; a primeira manifestação, relacionada com a própria evolução interna de nossa literatura, da nova etapa cultural aberta no mundo pela extensão da teoria e da práxis socialista. Esse primeiro ato é suficiente para valorizar a importância do movimento e para desmentir aqueles que se detêm em suas limitaçóes desde o ponto de vista de sua assepsia literária. Culturalmente, Boedo tem uma importância tão grande que toda a literatura de esquerda na Argentina (quer dizer, todo o corpo vivo da narrativa argentina) está marcada por seu selo. Inclusive suas limitações nascem do boedismo: da cristalização de hábitos trazidos pelo boedismo, explicáveis pelas condiçôes culturais em que o movimento se gestou, mas não tão justificáveis depois” (Idem). 


\section{Resumo}

\section{Boedo e Florida}

Este artigo discute os condicionantes históricos e sociais e os aspectos distintivos dos grupos que formaram as vanguardas argentinas na década de 1920. O autor desenvolve uma interpretação aguda sobre esse contexto, cujos significados - estético e político são avaliados.

Palavras-chave: Literatura argentina; Modernismo; Vanguardas; Ultraísmo; Literatura engajada.

\section{Abstract}

\section{Boedo and Florida}

This article discusses the historical and social conditioning factors and the distinctive aspects of the groups forming the Argentine avant-garde in the 1920s. The author provides a critical interpretation of this context and assesses its aesthetic and political meanings.

Keywords: Argentinean literature; Modernism; Avant-gardes; Ultraism; Politically committed literature. 